\title{
A Review of Factors Predicting Outcome of Pneumatic Dilation in Patients With Achalasia Cardia
}

\author{
Uday C Ghoshal* and Murali Rangan \\ Department of Gastroenterology, Sanjay Gandhi Postgraduate Institute of Medical Sciences, Lucknow, India
}

Pneumatic dilation (PD) is an effective treatment for achalasia cardia. Outcome of PD, however, varies among different studies. Recently, some groups started considering laparoscopic myotomy to be competitive to PD in treatment of achalasia considering dreaded complication like perforation following the latter therapeutic approach. Therefore, there is need to predict outcome of PD for achalasia, so that appropriate therapy, both for treatment naïve and for treatment failed patients can be chosen. Apart from age and gender, 2 investigations, namely post-PD manometry and timed barium esophagogram are most often used to predict outcome after PD. Even though there are studies available in the literature with regard to these modalities to predict outcome of PD, these are quite few in number, including small number of patients, primarily because of rarity of the disease. In this article, we review the literature predicting outcome of PD for achalasia.

(J Neurogastroenterol Motil 2011;17:9-13)

Key Words

Achalasia; Dysphagia; Esophageal dysmotility; Manometry

\section{Introduction}

Achalasia cardia is a rare primary esophageal motor disorder, which is diagnosed on the basis of esophageal manometry. ${ }^{1}$ Typical manometry findings in achalasia are aperistalsis of esophageal body and incomplete relaxation of lower esophageal sphincter (LES). ${ }^{2}$ Based on average esophageal body amplitude, achalasia is classified into classic ( $\leq 40 \mathrm{mmHg}$ ) and vigorous types $(>40 \mathrm{mmHg}) .{ }^{3}$ Vigorous achalasia is considered as the early stage in the natural history of the disease. ${ }^{4,5}$ Treatment of acha- lasia is usually palliative in nature. ${ }^{6}$ There are 3 main modes of therapy: pneumatic dilation (PD), botulinum toxin injection (both through endoscopic means) and surgery (Heller's cardiomyotomy). Endoscopic PD and surgery are effective in providing long-term remission. ${ }^{7}$

\section{Pneumatic Dilation}

$\mathrm{PD}$ is the most popular non-surgical treatment of achalasia. Moreover, it is cost-effective compared to botulinum toxin injection and surgery. ${ }^{8-10} \mathrm{PD}$ can be performed with different dila-

Received: June 16, 2010 Revised: July 5, 2010 Accepted: July 13, 2010

(c) This is an Open Access article distributed under the terms of the Creative Commons Attribution Non-Commercial License (http://creativecommons. org/licenses/by-nc/3.0) which permits unrestricted non-commercial use, distribution, and reproduction in any medium, provided the original work is properly cited.

*Correspondence: Uday C Ghoshal, MD, DNB, DM, FACG

Department of Gastroenterology, Sanjay Gandhi Postgraduate Institute of Medical Sciences, Raebareli Road, Lucknow 226014, India

Tel: +91-962-884-2456, Fax: +91-522-266-8017 (or 8078),E-mail: Udayghoshal@gmail.com

Financial support: None.

Conflicts of interest: None. 
tors of variable balloon compliances. Low compliance polyethylene pneumatic dilator (Rigiflex dilator) is most widely used because of its theoretical advantages over the high compliance balloon dilator. ${ }^{11}$ Most feared complication of PD is esophageal perforation. Perforation rate varies from less than $1 \%$ to $3 \%$ in various studies. ${ }^{12-16}$ Furthermore, PD is effective in $64 \%-87 \%$ patients. ${ }^{12}$ Also, a proportion of initial responders experience recurrence during long-term follow-up. Therefore, it is important to predict which patient is less likely to respond or develop recurrence following an initial response for the following reasons; (1) to devise treatment strategy in a given patient, (2) to prognosticate, (3) to plan early re-intervention, if required, and (4) to help understand pathophysiology of the disease. Table 1 shows the likely predictors of outcome following PD for achalasia cardia.

The studies published in literature addressing the issue on predictors of outcome of PD (Tables 1-3) differ in type of dilator used, symptom scores used to assess the outcomes (response and

Table 1. Possible Predictors of Outcome Following Pneumatic Dilation of Achalasia Cardia

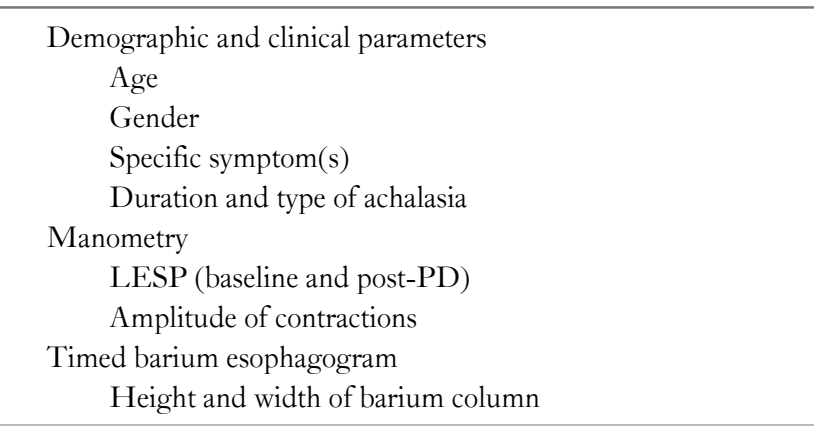

LESP, lower esophageal sphincter pressure; PD, pneumatic diation.

Table 2. Summary of Factors Useful to Predict Outcome of Pneumatic Dilation of Achalasia Cardia as Found in Different Studies

\begin{tabular}{|c|c|c|c|}
\hline $\begin{array}{l}\text { Author } \\
\text { and Year }\end{array}$ & $\begin{array}{l}\text { Patient } \\
\text { number }\end{array}$ & $\begin{array}{c}\text { Study } \\
\text { type }\end{array}$ & Predictor(s) \\
\hline Ponce, 1996 & 157 & $\mathrm{P}$ & $\begin{array}{l}\text { Age, sex, esophageal body } \\
\text { diameter and basal LESP }\end{array}$ \\
\hline Eckardt, 1992 & 54 & $\mathrm{P}$ & $\begin{array}{l}\text { Age, balloon diameter and } \\
\text { post-PD LESP }\end{array}$ \\
\hline Vaezi, 2004 & 75 & $\mathrm{R}$ & $\begin{array}{l}\text { Age, sex and timed barium } \\
\text { esophagogram }\end{array}$ \\
\hline Mehta, 2005 & 52 & $\mathrm{R}$ & Age \\
\hline Ghoshal, 2004 & 126 & $\mathrm{R}$ & Sex and post-PD LESP \\
\hline Chuah, 2009 & 32 & $\mathrm{P}$ & Age \\
\hline
\end{tabular}

$\mathrm{P}$, prospective study; R, retrospective study; LESP, lower esophageal sphincter pressure; $\mathrm{PD}$, pneumatic dilation. recurrence), treatment protocol for management of recurrence and investigations used to predict outcomes etc. In spite of such heterogeneity between the studies, these do provide valuable information, which can guide physician in planning treatment strategy.

The first large prospective study was done by Ponce et $\mathrm{al}^{17}$ in which 157 patients with achalasia underwent PD with Witzel dilator. Patients who had post-PD lower esophageal sphincter pressure (LESP) $<10 \mathrm{mmHg}$ had a better outcome than others. Using Bayes' theorem, a predictive model was constructed including 5 most discriminating values: age $<20$ years, male sex, diameter of esophageal body $<3 \mathrm{~cm}$, basal pressure of esophageal body $>15 \mathrm{mmHg}$ and LESP > $30 \mathrm{mmHg}$. Jackknife method was used to validate the model. The limitation of this study was lack of use of conventional statistics including multivariate analysis. Furthermore, Witzel dilator has high compliance balloon that is no longer in use.

Mehta et $\mathrm{al}^{18}$ reported a retrospective study on 52 patients using Rigiflex balloon in whom $81 \%$ responded to PD. On univariate analysis, non-responders were younger in age $(<40$ years), had high baseline LESP ( $>50 \mathrm{mmHg}$ ) and reduced mid-esophageal contractions (amplitude $<30 \mathrm{mmHg}$ ). There was no significant difference in response rates with respect to gender. On multivariate analysis, only young age was associated with poor response, though patients with high baseline LES pressure showed a trend towards poor response. Esophageal manometry was not repeated after PD in this study.

From our center, we reported a retrospective study on 126 patients who had undergone PD for achalasia. ${ }^{12}$ On univariate analysis, regurgitation, chest pain, pulmonary symptoms and male gender were associated with non-response. Post-PD reduction in LESP by more than $50 \%$ was associated with good response. On multivariate analysis, male gender was the only fac-

Table 3. Summary of Studies Predicting Outcome of Pneumatic Dilation of Achalasia Cardia

\begin{tabular}{ll}
\hline \multicolumn{1}{c}{ Predictors } & Outcome \\
\hline Old age $(>45 \mathrm{yr})$ & Favorable \\
Male gender & Poor \\
Large balloon size & Favorable \\
Post-PD LESP $<10 \mathrm{mmHg}$ & Favorable \\
Post-PD LESP reduction by $>50 \%$ & Favorable \\
Complete emptying in TBE & Favorable \\
\hline
\end{tabular}

PD, pneumatic dilation; LESP, lower esophageal sphincter pressure; TBE, timed barium esophagogram. 
tor, which was associated with worse outcome. This is the largest study in which a low compliance dilator (Rigiflex) was used. But, post-PD manometry was not done in all the patients in this study.

Eckardt et $\mathrm{al}^{19,20}$ reported outcome of management of 54 patients with achalasia cardia with PD. Symptom score and LESP were assessed at baseline and at 4 weeks after PD. Follow-up assessment of symptom score was done at 2 yearly intervals for a median of 13.8 years. Of 35 patients who had relapse, 32 relapsed within 5 years. Long-term outcome was significantly better in patients with age older than 40 years and post-PD LESP $<10$ $\mathrm{mmHg}$. Even though this study was prospective with long-term follow-up, the authors have used Brownie Mchardy dilator (high compliance balloon) which is not being used now-a-days.

Farhoomand et $\mathrm{al}^{21}$ reported a retrospective analysis of $75 \mathrm{pa}-$ tients who underwent PD with Rigiflex dilator. Symptom scoring and timed barium esophagogram were done in all the patients at baseline and at 1 month after PD. Among the patients who had undergone $\mathrm{PD}$ with $30 \mathrm{~mm}$ balloon, retreatment was required less often compared to the patients who had undergone PD with 35 and $40 \mathrm{~mm}$ balloon. Especially, early failure rate (within 3 months) was high among those who had undergone PD with 30 $\mathrm{mm}$ balloon compared to those in whom larger balloon diameter was used. Also, 22 of 25 patients who had early failure were men. Multivariate Cox proportional hazards model revealed that younger men ( $<45$ years) required additional therapy more frequently compared to older men and also the difference in response rate between male and female became narrower as age advanced. Thus they concluded that failure was commoner among young men who had undergone PD with $30 \mathrm{~mm}$ balloon. Similar to their previous study in which complete barium emptying in timed barium esophagogram was found to strongly correlate with symptomatic improvement, including long-term remission, this study also showed that those who did not require re-treatment more often had complete barium emptying after PD. ${ }^{22}$ Post-PD manometry was not done in this study. The authors suggested that male patients with achalasia should be treated with $35 \mathrm{~mm}$ balloon for even the first session of PD as $30 \mathrm{~mm}$ balloon often failed in them and post-PD timed barium esophagogram predicted long-term outcome after PD. A prospective study by Chuah et $\mathrm{al}^{23}$ on 32 patients managed with Rigiflex dilator also concluded that age more than 45 years was the only significant factor predicting favorable outcome.

Even though, some studies evaluated duration of dysphagia and type of achalasia as possible parameters predicting outcome, they were not found important in predicting outcome even in uni- variate analysis. ${ }^{12,17-19}$ Post-PD manometry and timed barium esophagogram are the 2 most widely used investigations to predict the outcome after PD. Manometry studies have used various criteria to predict the outcome such as post-PD LESP $<10$ $\mathrm{mmHg}$ and reduction of LESP by more than $50 \%$ of baseline LESP.

Andersson et $\mathrm{al}^{24}$ reported a prospective study, in which 51 patients with achalasia were randomized into 2 treatment groups, namely PD and laparoscopic myotomy. Timed barium esophagogram was done at baseline and after treatment. The median follow-up time after the post-treatment timed barium esophagogram was 18 months. They found a significant correlation between barium emptying at 1 minute and symptom scores at the end of follow-up period in both the groups. Patients with less than $50 \%$ improvement in this parameter after treatment had a $40 \%$ risk of treatment failure on follow-up.

The recently introduced high resolution manometry displays spatiotemporal plots of esophageal body and LESPs. ${ }^{25,26}$ It also helps us to understand the segmental functional anatomy of esophageal body and LES, which contributes to our understanding of various subsets of achalasia and possibly their difference in response to various modes of treatment. Till now, this attractive research tool has not been studied for predicting the outcome of PD in achalasia.

\section{Why Is Pneumatic Dilation Less Effective in Men?}

Explanation for worse outcome of PD among men is unknown. However, one may hypothesize that LES muscles might be stronger among men than women that might be responsible for worse outcome among them. LES tone might be more in younger men than in older men, thus further explaining less favorable outcome in young men. However, this needs to be studied further.

\section{Why Is Old Age a Favorable Predictor? -}

Apart from some of the above discussed studies, there are many other studies in literature which concluded old age as a predictor of favorable outcome. ${ }^{27-30}$ Though, the exact reason for this is not known, there are various hypotheses to explain this finding.

Anatomically, LES has 2 components, namely clasp fibers encircling the gastroesophageal junction medially and gastric sling fibers present on left lateral side. In PD, only the clasp fi- 
bers are targeted. Hence, it is possible that gastric sling fibers, unaffected by PD, contribute to residual LES tone in these patients after PD. As discussed previously, this tone is likely to be higher in younger patients, thus explaining poor response in young patients. ${ }^{31}$ Patients with long-standing symptoms often interpret mild improvement in esophageal emptying as dramatic relief from dysphagia. ${ }^{32}$ Older patients perceive less pain compared to their younger counterparts when balloon is distended in esophagus. ${ }^{33}$ Also, older patients are expected to have weaker LES muscles that might be easily torn during PD.

\section{Clinical Implications}

Young men having persistently high LESP and poor esophageal emptying after PD might be better treated by laparoscopic myotomy rather than persisting with repeated PDs. Similarly, old women after PD having low (or $>50 \%$ reduced) LESP and good esophageal emptying may be offered repeated PD in the unlikely event of recurrence. Thirty-five $\mathrm{mm}$ instead of $30 \mathrm{~mm}$ balloon should be tried for first PD, particularly in males.

\section{Need for Future Research}

A prospective study with large number of patients and long-term follow-up is needed. Both timed barium esophagogram and manometry, especially high resolution manometry should be done at baseline and post-PD, so that they can be compared in their value in predicting outcome. Strong statistical methods will add to the strength of evidence.

\section{Conclusion}

$\mathrm{PD}$ is an effective alternative to surgery. The response to PD depends on age and gender of the patient and size of the balloon used for PD. The long-term response can be predicted with the help of post-PD manometry and timed barium esophagogram. Balloon size has to be chosen according to the gender. Further prospective studies with larger numbers are needed.

\section{References}

1. Farrokhi F, Vaezi MF. Idiopathic (primary) achalasia. Orphanet J Rare Dis 2007;2:38-46.

2. Eckardt AJ, Eckardt VF. Current clinical approach to achalasia. World J Gastroenterol 2009;15:3969-3975.

3. Goldenberg SP, Burrell M, Fette GG, Vos C, Traube M. Classic and vigorous achalasia: a comparison of manometric, radiographic, and clinical fingings. Gastroenterology 1991;101:743-748.

4. Misra A, Chourasia D, Ghoshal UC. Manometric and symptomatic spectrum of motor dysphagia in a tertiary referral center in northern India. Indian J Gastroenterol 2010;29:12-16.

5. Park W, Vaezi MF. Etiology and pathogenesis of achalasia: the current understanding. Am J Gastroenterol 2005;100:1404-1414.

6. Chuah SK, Wu KL, Hu TH, Tai WC, Changchien CS. Endoscope guided pneumatic dilation for treatment of esophageal achalasia. World J Gastroenterol 2010;16:411-417.

7. Lopushinsky SR, Urbach DR. Pneumatic dilatation and surgical myotomy for achalasia. JAMA 2006;296:2227-2233.

8. Ghoshal UC, Aggarwal R, Kumar S, Naik SR. Pneumatic dilation versus intrasphincteric botulinum toxin injection in the treatment of achalasia cardia in India: an economic analysis. Indian J Gastroenterol 2002;21:193-196.

9. Parkman HP, Reynolds JC, Ouyang A, Rosato EF, Eisenberg JM, Cohen S. Pneumatic dilatation or oesophagomyotomy treatment for idiopathic achalasia: clinical outcomes and cost analysis. Dig Dis Sci 1993;38:75-85.

10. Richter JE. Comparison and cost analysis of different treatment strategies in achalasia. Gastrointest Endosc Clin N Am 2001;11:359-370.

11. Stark GA, Castell DO, Richter JE, Wu WC. Prospective randomized comparison of Brown-McHardy and microvasive balloon dilators in treatment of achalasia. Am J Gastroenterol 1990;85:13221326.

12. Ghoshal UC, Kumar S, Saraswat VA, Aggarwal R, Misra A, Choudhuri G. Long-term follow-up after pneumatic dilation for achalasia cardia: factors associated with treatment failure and recurrence. Am J Gastroenterol 2004;99:2304-2310.

13. Khan AA, Shah WH, Alam A, Butt AK, Shafqat F. Sixteen years of follow up of achalasia: a prospective study of graded dilatation using Rigiflex balloon. Dis Esophagus 2005;18:41-45.

14. Vela MF, Richter JE, Wachsberger D, Connor J, Rice TW. Complexities of managing achalasia at a tertiary referral centre: use of pneumatic dilatation, Heller myotomy, and botulinum toxin injection. Am J Gastroenterol 2004;99:1029-1036.

15. Metman EH, Lagasse JP, d'Alteroche L, Picon L, Scotto B, Barbieux JP. Risk factors for immediate complications after progressive pneumatic dilation for achalasia. Am J Gastroenterol 1999; 94:1179-1185.

16. Bittinger M, Wienbeck M. Pneumatic dilation in achalasia. Can J Gastroenterol 2001;15:195-199.

17. Ponce J, Garrigues V, Pertejo V, Sala T, Berenguer J. Individual prediction of response to pneumatic dilation in patients with achalasia. Dig Dis Sci 1996;41:2135-2141.

18. Mehta R, John A, Sadasivan S, et al. Factors determining successful outcome following pneumatic balloon dilation in achalasia cardia. Indian J Gastroenterol 2005;24:243-245.

19. Eckardt VF, Aignherr C, Bernhard G. Predictors of outcome in patients with achalasia treated by pneumatic dilation. Gastroenterology 1992;103:1732-1738.

20. Eckardt VF, Gockel I, Bernhard G. Pneumatic dilation for achalasia: late results of a prospective follow up investigation. Gut 2004;53: 629-633.

21. Farhoomand K, Connor JT, Richter JE, Achkar E, Vaezi MF. Pre- 
dictors of outcome of pneumatic dilation in achalasia. Clin Gastroenterol Hepatol 2004;2:389-394.

22. Vaezi MF, Baker ME, Achkar E, Richter JE. Timed barium oesophagram: better predictor of long term success after pneumatic dilation in achalasia than symptom assessment. Gut 2002;50:765-770

23. Chuah SK, $\mathrm{Hu} \mathrm{TH}, \mathrm{Wu} \mathrm{KL}$, et al. Clinical remission in endoscope-guided pneumatic dilation for the treatment of esophageal achalasia: 7-year follow-up results of a prospective investigation. J Gastrointest Surg 2009;13:862-867.

24. Andersson M, Lundell L, Kostic S, et al. Evaluation of the response to treatment in patients with idiopathic achalasia by the timed barium esophagogram: results from a randomized clinical trial. Dis Esophagus 2009;22:264-273.

25. Fox MR, Bredenoord AJ. Oesophageal high-resolution manometry: moving from research into clinical practice. Gut 2008;57:405-423.

26. Pandolfino JE, Kwiatek MA, Nealis T, Bulsiewicz W, Post J, Kahrilas PJ. Achalasia: a new clinically relevant classification by high-resolution manometry. Gastroenterology 2008;135:1526-1533.

27. Fellows IW, Ogilvie AL, Atkinson M. Pneumatic dilation in ac- halasia. Gut 1983;24:1020-1023.

28. Vantrappen G, Hellemans J, Deloof W, Valembois P, Vandenbrouke J. Treatment of achalasia with pneumatic dilations. Gut 1971;12:268-275.

29. Dağli U, Kuran S, Savaş N, et al. Factors predicting outcome of balloon dilatation in achalasia. Dig Dis Sci 2009;54:1237-1242.

30. Tanaka Y, Iwakiri K, Kawami N, et al. Predictors of a better outcome of pneumatic dilatation in patients with primary achalasia. J Gastroenterol 2010;45:153-158.

31. Pehlivanov N, Pasricha PJ. Medical and endoscopic management of achalasia. GI Motility online 2006. www.nature.com/gimo/contents/pt1/full/gimo52.html

32. Gelfand MD, Kozarek RA. An experience with polyethylene balloons for pneumatic dilation in achalasia. Am J Gastroenterol 1989; 84:924-927.

33. Lasch H, Castell DO, Castell JA. Evidence for diminished visceral pain with aging: studies using graded intraesophageal balloon distension. Am J Physiol 1997;272:G1-G3. 